\title{
Knowledge and Awareness about Diabetes Mellitus and Gestational Diabetes Mellitus - Review
}

Sangeetha Thomas*

\begin{abstract}
The paper aims to review the previous literature conducted till date on knowledge of Diabetes Mellitus (DM) and Gestational Diabetes Mellitus (GDM) across the globe, focussing more on the studies from the Indian context. The review posits that the knowledge and awareness of Diabetes and Gestational Diabetes among the larger population needs attention. Additionally, knowledge of the risks and complications is low among participants. Significantly limited literature was available on antenatal women and on the provision of awareness programmes for such participants. The review concludes with the observation that the knowledge and awareness about DM and GDM has important implications for public health policies and specifically for the implementation of National Diabetes Prevention/Control Programmes.
\end{abstract}

Keywords: Diabetes Mellitus, Gestational Diabetes Mellitus, Antenatal Women

\section{Introduction}

Diabetes Mellitus (DM) can be classified into three broad categories which include Type 1, Type 2 and Gestational Diabetes (GDM). Type 2 Diabetes (non-insulin-dependent diabetes mellitus/adult-

\footnotetext{
* CHRIST (Deemed to be University), Bengaluru, India; : sangeetha.thomas@christuniversity.in
} 
onset diabetes) is a metabolic disorder that is characterised by high blood glucose due to insulin resistance/insulin deficiency (Shivashankar, \& Mani, 2011). GDM develops when carbohydrate intolerance occurs during pregnancy (Hoffman et al., 1998).

\section{Knowledge about DM}

The awareness and knowledge about DM were assessed among the general population by Deepa et al. (2014) in four selected regions of India. There was a significant disparity in the level of knowledge between different regions. Based on a composite knowledge score among the population studied, Tamil Nadu had the highest score whereas Jharkhand had the lowest score. The majority of the participants of the study by Muninarayana, Balachandra, Hiremath, Iyengar, \& Anil (2010), Lorga, Srithong, Manokulanan, Aung, \& Aung (2012), Unadike \& Chineye (2009), Ulvi et al. (2009) were unaware of DM itself. Murugesan, Snehalatha, Shobhana, Roglic and Ramachandran (2007) studied the levels of awareness of DM amidst the Indian population. The low median score was obtained which indicated that the awareness was poor among the participants. While few other studies remarked on variations in the knowledge of DM among participants (Fezeu, Fointama, Ngufor, Mbeh \& Mbanya, 2010; Mahajerin, Fras, Vanhecke \& Ledesma, 2008).

\subsection{Risk Factors, Complications and Management of DM}

Deepa et al. (2014), Mumu, Saleh, Ara, Haque, \& Ali (2014) and Ulvi, et al. (2009) found that the majority of participants were unaware of the associated risk factors. Contrary findings were found in the study by Wee, Ho, \& Li (2002). Mohan et al. (2005) found that knowledge of the role of obesity and physical inactivity as a risk in producing DM was very low. The prevalence of risk behaviour for DM included tobacco and alcohol use, diet, and physical inactivity among select participants (Singh, Milton, Nanaiah, Samuel \& Thomas, 2012). It needs to be noted that obesity was not reported as a risk factor for DM by the majority of participants (Deepa et al., 2014).

The knowledge of the disease and its complications was found to be unsatisfactory in both diabetic and non-diabetic groups (Das et 
al., 2014).The overall knowledge regarding DM complications was more in diabetic women in comparison to non-diabetic participants and was found to be statistically significant (Das et al., 2014). Knowledge regarding long term complications of DM was poor in the studies conducted by Babaee, Soltanian, Khalkhaly, Rabieian, Bahreini, and Afkhami (2007), Gulabani, John, and Isaac (2008), Joshi et al. (2008), Mohan et al. (2005), Munninarayana et al.(2010), Singh et al. (2012) and Ulvi et al. (2009). Das et al. (2014) found that the knowledge regarding the complications associated with eye, kidney and foot problems were similar for diabetic and nondiabetic groups while knowledge regarding cardiac issues was found to be significantly different from the non-diabetic group. Only $19.0 \%$ (4951/26001) of the whole population in Chennai knew that DM could cause cardiac complications (Mohan et al., 2005).

The knowledge regarding management also depicted serious deficits. Only $31 \%$ of the student participants of Unadike et al. (2009) agreed that reducing weight was an important aspect of managing diabetes. Most of the respondents were not aware of the importance of a diet in the management of DM (Babaee et al., 2007; Wee et al., 2002) but knowledge about the controlling methods was high (Choi, Oh, Hur, Lee, \& Choi, 2000).

\subsection{Educational Status, Family History, Gender and Age}

Most of the studies have depicted a direct relation between knowledge about DM and the level of education (Babaee et al., 2007; Bruce, Davis, Cull, \& Davis, 2003; Çaliskan, Ozdemir, Ocaktan, \&Idil, 2006; Deepa et al., 2014; Fezeu, et al., 2010; Murugesan et al., 2007) but contrary findings were obtained from the study conducted by Ulvi et al. (2009).

Fezeu et al.(2010) and Ulvi et al. (2009) found that the family history of DM played an important role in the awareness of DM. They state that the majority of people who were aware of DM were aware because of an affected family member.

The current literature assessing the relationship between gender and knowledge of DM yielded varied findings, with a few reporting that gender was a determinant of knowledge of DM (Çaliskan et al., 2006; Ghaffar et al., 2004; Gulabani et al., 2008; Legato et al., 2006; Lorga et al., 2012; Murata et al., 2003; 
Murugesan et al., 2007) whereas others did not (Gunay, Ulusel, Velipasaoglu, Unal, Ucku, \& Ozgener, 2006; Pongmesa, Li, \& Wee, 2009; Ulvi et al., 2009; Yun, Hassan, Aziz, Awaisu, \& Ghazali, 2007). In the Indian context, women had a low awareness rate about DM compared to men in all regions except Chandigarh (Deepa et al., 2014).

In a study by Pongmesa et al. (2009), respondents who were aged 45 years or older had better knowledge than the younger respondents. This was consistent with several studies that found a positive relationship between age and knowledge of DM (Ding, Teng, \& Koh, 2006; Wee et al., 2002). Further, while some studies found a lower level of knowledge of DM among older people (Babaee et al., 2007; Bruce et al., 2003; Çaliskan et al., 2006; He \& Wharrad, 2007; Hussain, Yusoff, \& Sulaiman, 2014; Murata, et al., 2003), other studies revealed no association between age and knowledge of DM (Gunay et al., 2006; Murugesan et al., 2007; Yun et al., 2007).

\subsection{Sources of Knowledge and DM across the Rural/Urban Area}

Studies conducted in India have identified a variety of sources for obtaining information on DM. Bruce et al. (2003) state that knowledge of DM is gained through attending education programmes and visiting a dietician. Çaliskan et al. (2006) concluded that primary health care centres play a small role in the dissemination of information on diabetics.

The knowledge of DM in rural and urban parts has yielded similar results. Both rural and urban areas have low knowledge of diabetes. Muninarayana et al. (2010), Singh et al. (2012) and Ulvi et al. (2009) showed that relevant knowledge of DM is poor in the rural population. Das et al. (2014) and Mohan et al (2005) state that awareness and knowledge regarding DM are still exceptionally inadequate in urban parts of India. But comparative studies revealed that awareness and knowledge of DM are significantly higher in urban areas than in rural areas (Deepa et al., 2014).

The literature on knowledge of $\mathrm{DM}$ has revealed that the understanding of DM is low. The knowledge of its risk factors, complications and management is required for ensuring better 
Sangeetha Thomas Knowledge and Awareness about Diabetes Mellitus

treatment and control of DM. The findings have depicted that the knowledge about DM is grossly inadequate in India.

\section{Knowledge about GDM}

A literature search for knowledge on GDM has yielded only a few studies. A cross-sectional study was conducted in Tamil Nadu among 360 antenatal women to assess their level of awareness about GDM. The results revealed that $88 \%$ of them are aware of GDM, 60\% did not know that GDM can recur and 56\% were not aware of the treatment. The knowledge about the risk factors and complications of GDM is poor among antenatal women (Mahalaksmi, Stanely, \& Vanisree, 2013).

Carolan, Steele and Margetts (2010) tried to understand the level of knowledge about GDM among a multi-ethnic sample of women who were diagnosed with GDM. A cross-sectional comparative survey was conducted among 143 pregnant women from Vietnamese, Indian, Filipino and Caucasian backgrounds. Vietnamese, Filipino and Caucasian women displayed poor knowledge of GDM. Women from the Middle East did not know of GD and Swedish women attributed GD to inheritance, environment and hormonal changes. Indian women scored the highest among the sample (Hjelm, Bard, Nyberg, \& Apelqvist, 2005).

Gastrich, Peck, Janevic, Bachmann, Lotwala and Siyam (2013) assessed GDM knowledge and beliefs of 85 pregnant women during their first antepartum visit. It was found that their knowledge was deficient. These results confirm the results of previous studies (Carolan et al., 2010; Metzger et al., 2007). Shriraam, Rani, Sathiyasekaran and Mahadevan (2013) assessed the awareness among the antenatal women who attended a Primary Health Center (PHC) about GDM. The result indicated that $25.8 \%$ of women had poor knowledge about GDM. It was observed that there was a significant difference in knowledge among those previously diagnosed with GDM as compared to those who had not been diagnosed (Gastrich et al., 2013). Choi et al. (2000) and Rolim, De Souza, Paulino, Bezerra and Coelh (2012) found that pregnant women showed superficial knowledge about gestational 
diabetes. Choi, Oh and Park (2001) investigated the knowledge of nurses about GDM. It was found that there were significant differences according to the working period, working unit, working experience of obstetric and gynecologic units, the experience of pregnancy and the experience of delivery in GDM knowledge.

From the literature search, only two studies were identified from the Indian subcontinent. After all the studies of GDM were conducted among antenatal women, it was observed that the knowledge about the condition is generally poor among women.

\subsection{Risk Factors, Complications and Management of GDM}

Various studies have identified different risk factors of GDM. Age, obesity, ethnicity, family history of DM and a history of GDM were determined as risk factors (Clapperton, Jarvis, \&Mungrue, 2009). $32 \%$ of antenatal women who participated in the study knew one or more risk factors associated with GDM (Mahalaksmi et al., 2013). Women who developed GDM during their second trimester of pregnancy had better knowledge of risk factors (age and higher BMI) (Huidobro, Prentice, Fulford, Parodi \& Rozowski, 2010). The results of the knowledge of risk factors have not been satisfactory with many participants with low awareness.

Mahalaksmi et al. (2013) found that among 360 antenatal women, only $12 \%$ were aware of one or more maternal complications and $16 \%$ knew about one or more of the fetal complications. This depicts the low knowledge among antenatal women. The awareness that untreated GDM can cause a risk to the unborn child was high among women included few studies (Shriraam et al. (2013). Similar findings were obtained by Choi et al. (2000) where pregnant women knew very well that GDM women have more maternal and fetal complications than normal pregnant women. The results showed that the participants have a minimal level of understanding about the knowledge regarding the complications.

Hussain et al. (2014) found that participants had the lowest knowledge of the management of GDM. They identified a number of factors that hinder the task of effective GDM self-management. Barriers include time pressures, physical constraints, social constraints, limited comprehension of requirements, and they 
reported that taking insulin shots was an easier option. Thoughts about the baby, psychological support from partners and families were powerful motivators for the adherence to GDM management regimens (Carolan, 2013; Carolan, Gill \& Steele, 2012).

Tabassam, Sadaqat, Mahmood and Zaka (2010) state the importance of intervention in the management of GDM. In the case of GDM, the lack of effective management can lead to further complications. But the studies have shown limited understanding of patients regarding effective management.

\subsection{Education, Family History, Age and Rural/Urban Area}

Educational level seems to be the most significant predictor of GDM knowledge (Al Shafaee et al. 2008; Carolan et al., 2010; Carolan, Steele, \& Margetts, 2010; Choi et al., 2000; Choi et al., 2001; Hussain et al., 2014). Many studies have depicted that family history plays a significant role in creating awareness among participants. Choi et al. (2000) and Huidobro et al. (2010) found that pregnant women who had DM patients in their families were more knowledgeable about GDM. Hussain et al. (2014) found that the highest mean knowledge score among GDM patients was recorded based on the family history of DM.

There was a significant difference in the knowledge of GDM with respect to age. Pregnant women more than 30 years old were more knowledgeable about GDM (Choi et al., 2000; Choi et al., 2001). There are few studies which measure the knowledge about GDM in rural and urban areas and no comparative studies have been identified. Shriraam et al. (2013) identified that only a limited percentage of rural antenatal women had good knowledge about GDM.

\subsection{Sources of Obtaining Knowledge and Need for Public Awareness}

The major sources of awareness of GDM among antenatal women were television/radio, neighbours/friends, nurses and midwives and family members (Shriraam et al., 2013; Carolan et al., 2010). Low knowledge level among participants regarding GDM cites the need for the development of new educational strategies to address lower health literacy (Carolan et al., 2010). 
Gastrich et al. (2013) recommended the importance of health education on GDM among women both prior to conception and during the period of gestation. An educational activity for creating awareness among pregnant women about the GDM acts as an integral part of prenatal care (Biral, Cardoso \& Grunspan, 2005; Rolimet al., 2012).

\section{Conclusion}

The studies cited above, conducted across the world, have analysed the knowledge levels of DM. Most of the studies have concluded that knowledge of DM is low. Only a few studies on DM have concluded that participants had a fair knowledge of DM. The studies have shown a mixed finding regarding the age and knowledge of DM. Education plays a key role in the knowledge level thereby leading to effective management of the illness. A large number of studies have been conducted on developing the knowledge of DM and only a few have cited the importance of awareness programmes.

While considering the knowledge about GDM, it was found that participants exhibited low knowledge across different dimensions. Studies have been conducted specifically on antenatal women with or without GDM. It is seen that studies conducted among Indian pregnant women are also few. Further on, there are very few studies which measure the knowledge of GDM in rural and urban areas and no comparative studies have been conducted.

A limited number of studies have yielded the role of age, education, place of residence in knowledge regarding gestational diabetes. GDM poses a risk not only for the mother but also for the baby. Knowledge is one of the key components in ensuring better management of GDM. Poor knowledge regarding various aspects of GDM is associated with poor health. As the prevalence rate is increasing, knowledge regarding prevention and management has a critical role. Therefore in the context of increasing prevalence, there is a need to draw attention to the Indian population in imparting better knowledge and awareness about DM.

Comprehensive knowledge about the illness is required to prevent and manage it effectively especially during the time of gestation. 
The understanding of the risks, complications and management will help prevent illness and promote wellbeing. Further exploration of these aspects is required for better understanding and effective management and prevention. The understanding of knowledge and awareness about DM and GDM can help to plan the public health policies with specific reference to the implementation of national diabetes prevention/control programmes. Thus, the above study is an attempt to draw light in the Indian scenario, towards awareness, prevention and care.

\section{References}

Al Shafaee, M. A., Al-Shukaili, S., Rizvi, S. G., Al Farsi, Y., Khan, M. A., Ganguly, S. S., ... \& Al Adawi, S. (2008). Knowledge and perceptions of diabetes in a semi-urban Omani population. BMC Public Health, 8(1), 249. doi:10.1186/1471-2458-8-249

Babaee, Q. R., Soltanian, A. R., Khalkhaly, H. R., Rabieian, M., Bahreini, F., \& Afkhami Ardekani, M. (2007). People's awareness on diabetes disease and complications in Bushehr, Iran using Linears Models. Payavard Salamat, 1(1), 52-58. Retrieved from http:// payavard.tums.ac.ir/index.php?slc_lang $=$ en\&sid $=1$

Biral, A. M., Cardoso, P. M., \& Grunspan, S. (2005). Importância doeducadorem Diabetes Mellitus. Diabetes Clínica, 9(3), 193-9. Retrieved from http://www.clinicadadiabetes.pt/

Bruce, D. G., Davis, W. A., Cull, C. A., \& Davis, T. M. (2003). Diabetes education and knowledge in patients with type 2 diabetes from the community: the Fremantle Diabetes study. Journal of Diabetes and its Complications, 17(2), 82-89. doi: 10.1016/S1056-8727(02)00191-5

Çaliskan, D., Ozdemir, O., Ocaktan, E., \&Idil, A. (2006). Evaluation of awareness of diabetes mellitus and associated factors in four health center areas. Patient Education and Counseling,62(1), 142-147.doi: 10.1016/j.pec.2005.06.018

Carolan, M. (2013). Women's experiences of gestational diabetes selfmanagement: a qualitative study. Midwifery, 29(6), 637-645. doi: 10.1016/j.midw.2012.05.013

Carolan, M., Gill, G. K., \& Steele, C. (2012). Women's experiences of factors that facilitate or inhibit gestational diabetes self-management. BMC Pregnancy and Childbirth, 12(1), 99. doi:10.1186/ 1471-2393-12-99 
Carolan, M., Steele, C., \& Margetts, H. (2010). Attitudes towards gestational diabetes among a multiethnic cohort in Australia. Journal of Clinical Nursing, 19(17-18), 2446-2453. doi: 10.1111/j.13652702.2010.03305.x

Carolan, M., Steele, C., \& Margetts, H. (2010). Knowledge of gestational diabetes among a multi-ethnic cohort in Australia. Midwifery, 26(6), 579-588. doi: 10.1016/j.midw.2009.01.006

Choi, E. S., Oh, J. A., \& Park, J. S. (2001). A study of nurses knowledges on Gestational Diabetes Mellitus. Korean Journal of Women Health Nursing, 7(4), 419-431. Retrieved from http:// koreamed.org/ SearchBasic.php

Choi, E. S., Oh, J. A., Hur, M. H., Lee, I. S., \& Choi, S. Y. (2000). The knowledge and learning needs about Gestational Diabetes in pregnant women. Journal of Korean Academy of Women's Health Nursing, 6(1), 96108. Retrieved from http://koreamed.org/SearchBasic.php

Clapperton, M., Jarvis, J., \& Mungrue, K. (2009). Is gestational diabetes mellitus an important contributor to metabolic disorders in Trinidad and Tobago? Obstetrics and Gynecology International, 2009. doi: dx.doi.org/10.1155/2009/289329

Das, S. M., Mukherjee, S., \& Baran, A. (2014). Knowledge regarding Diabetes among women residing in Kolkata, West Bengal, India. Journal of Dental and Medical Sciences, 13 (4), 41-14.Retrieved from http://www.iosrjournals.org/

Deepa, M., Bhansali, A., Anjana, R. M., Pradeepa, R., Joshi, S. R., Joshi, P. P., ... \& Kaur, T. (2014). knowledge and awareness of diabetes in urban and rural India: The Indian Council of Medical Research India Diabetes Study (Phase I): Indian Council of Medical Research India Diabetes 4. Indian Journal of Endocrinology and Metabolism, 18(3), 379. doi: $10.4103 / 2230-8210.131191$

Ding, C. H., Teng, C. L., \& Koh, C. N. (2006). Knowledge of diabetes mellitus among diabetic and non-diabetic patients in Klinik Kesihatan Seremban. The Medical Journal of Malaysia, 61(4), 399-404. Retrieved from http://europepmc.org/

Fezeu, L., Fointama, E., Ngufor, G., Mbeh, G., \&Mbanya, J. C. (2010). Diabetes awareness in general population in Cameroon. Diabetes Research and Clinical Practice, 90(3), 312-318. doi: http:// dx.doi.org/ 10.1016/j.diabres.2010.06.029 
Gastrich, M. D., Peck, S., Janevic, T., Bachmann, G., Lotwala, N., \&Siyam, A. (2013). Gestational Diabetes Mellitus: an educational opportunity. Journal of Diabetes Nursing,17(6). Retrieved from http:/ / www.thejournalofdiabetesnursing.co.uk/

Ghaffar, A., Reddy, K. S., \&Singhi, M. (2004). Burden of noncommunicable diseases in South Asia. BMJ, 328(7443), 807-810.doi: http:/ / dx.doi.org/10.1136/bmj.328.7443.807

Gulabani, M., John, M., \& Isaac, R. (2008). Knowledge of diabetes, its treatment and complications amongst diabetic patients in a tertiary care hospital. Indian Journal of Community Medicine: Official Publication of Indian Association of Preventive $\mathcal{E}$ Social Medicine, 33(3), 204. doi: $10.4103 / 0970-0218.42068$

Gunay, T., Ulusel, B., Velipasaoglu, S., Unal, B., Ucku, R., \& Ozgener, N. (2006). Factors affecting adult knowledge of diabetes in Narlidere Health District, Turkey. Acta Diabetologica,43(4), 142-147. doi: $10.1007 /$ s00592-006-0230-6

He, X., \& Wharrad, H. J. (2007). Diabetes knowledge and Glycemic control among Chinese people with type 2 diabetes. International nursing review, 54(3), 280-287. doi: 10.1111/j.1466-7657.2007.00570.x

Hjelm, K., Bard, K., Nyberg, P., \& Apelqvist, J. (2005). Swedish and Middle-Eastern-born women's beliefs about gestational diabetes. Midwifery, 21(1), 44-60. doi: 10.1016/j.midw.2004.09.004

Hoffman, L., Nolan, C., Wilson, J. D., Oats, J. J., \& Simmons, D. (1998). Gestational diabetes mellitus-management guidelines-The Australasian Diabetes in Pregnancy Society. Medical Journal of Australia, 169(2), 93-97. Retrieved from http:/ / ecite.utas.edu.au/13534

Huidobro, A., Prentice, A., Fulford, T., Parodi, C., \& Rozowski, J. (2010). Gestational diabetes, comparison of women diagnosed in second and third trimester of pregnancy with non GDM women: Analysis of a cohort study. Rev Med Chile, 3, 316-21. doi: /S0034-98872010000300009.

Hussain, Z., Yusoff, Z. M., \& Sulaiman, S. A. S. (2014). Evaluation of knowledge regarding gestational diabetes mellitus and its association with glycaemic level: A Malaysian study. Primary Care Diabetes. doi: 10.1016/j.pcd.2014.07.007

Joshi, S. R., Das, A. K., Vijay, V. J., \& Mohan, V. (2008). Challenges in diabetes care in India: sheer numbers, lack of awareness and inadequate control. Journal of the Association of Physicians of India, 56, 443-450. Retrieved from http:/ / www.ncbi.nlm.nih.gov 
Legato, M. J., Gelzer, A., Goland, R., Ebner, S. A., Rajan, S., Villagra, V., \& Kosowski, M. (2006). Gender-specific care of the patient with diabetes: review and recommendations. Gender Medicine, 3(2), 131-158. Retrieved from http://www.ncbi.nlm.nih.gov

Lorga, T., Srithong, K., Manokulanan, P., Aung, T. N. N., \& Aung, M. N. (2012). Public knowledge of diabetes in Karen Ethnic rural residents: a community-based questionnaires study in the far north-west of Thailand. International Journal of General Medicine, 5, 799. doi: 10.2147/IJGM.S33177Ma

Mahajerin, A., Fras, A., Vanhecke, T. E., \& Ledesma, J. (2008). Assessment of knowledge, awareness, and self-reported risk factors for type II diabetes among adolescents. Journal of Adolescent Health,43(2), 188190. doi: 10.1016/j.jadohealth.2007.12.019

Mahalakshmi, B., Stanly, A.M., \& Vanishree (2013)Awareness about Gestational Diabetes Mellitus among Antenatal Women Attending tertiary clinic. International Journal of Scientific Research, 2(10). Retrieved from http:/ / www.ijem.in/temp/IndianJEndocrMetab1711467017852_192938.pdf

Metzger, B. E., Buchanan, T. A., Coustan, D. R., De Leiva, A., Dunger, D. B., Hadden, D. R., ... \& Zoupas, C. (2007). Summary and recommendations of the fifth international workshop-conference on gestational diabetes mellitus. Diabetes Care, 30(Supplement 2), S251S260. doi: $10.2337 /$ dc07-s225

Mohan, D., Raj, D., Shanthirani, C. S., Datta, M., Unwin, N. C., Kapur, A., \& Mohan, V. (2005). Awareness and Knowledge of diabetes in Chennai-The Chennai urban rural epidemiology study [CURES9]. Journal of the Association of Physicians of India, 53, 283-287. Retrieved from www.japi.org/april2005/O-283.pdf

Mumu, S. J., Saleh, F., Ara, F., Haque, M. R., \& Ali, L. (2014). Awareness regarding risk factors of type 2 diabetes among individuals attending a tertiary-care hospital in Bangladesh: a cross-sectional study. BMC Research Notes, 7(1), 599. doi:10.1186/1756-0500-7-599

Muninarayana, C., Balachandra, G., Hiremath, S. G., Iyengar, K., \& Anil, N. S. (2010). Prevalence and awareness regarding diabetes mellitus in rural Tamaka, Kolar. International journal of Diabetes in Developing Countries, 30(1), 18. Retrieved from http:// www.ncbi.nlm.nih.gov/ pmc/articles/PMC2859279/ 
Muninarayana, C., Balachandra, G., Hiremath, S. G., Iyengar, K., \& Anil, N. S. (2010). Prevalence and awareness regarding diabetes mellitus in rural Tamaka, Kolar. International Journal of Diabetes in Developing Countries, 30(1), 18. Retrieved from http:// www.ncbi.nlm.nih.gov/ pmc/articles/PMC2859279/

Murata, G. H., Shah, J. H., Adam, K. D., Wendel, C. S., Bokhari, S. U., Solvas, P. A., ... \& Duckworth, W. C. (2003). Factors affecting diabetes knowledge in Type 2 diabetic veterans. Diabetologia, 46(8), 1170-1178. doi: 10.1007/s00125-003-1161-1

Murugesan, N., Snehalatha, C., Shobhana, R., Roglic, G., \& Ramachandran, A. (2007). Awareness about diabetes and its complications in the general and diabetic population in a city in southern India. Diabetes Research and Clinical Practice, 77(3), 433-437. Retrieved from http://www.ncbi.nlm.nih.gov

Pongmesa, T., Li, S. C., \& Wee, H. L. (2009). A survey of knowledge on diabetes in the central region of Thailand. Value in Health, 12(s3), S110S113. doi: 10.1111/j.1524-4733.2009.00641.x

Rolim de Holanda, V., De Souza, M. A., Paulino dos Santos Rodrigues, M. C., Bezerra Pinheiro, A. K., \& Coelho Damasceno, M. M. (2012). Knowledge of pregnant women about gestational diabetes mellitus. Journal of Nursing UFPE/Revista de Enfermagem UFPE, 6(7). Retrieved from http://www.revista.ufpe.br/ revistaenfermagem/ index.php/ revista

Shivashankar, M., \& Mani, D. (2011). A brief overview of diabetes. International Journal of Pharmacy and Pharmaceutical Sciences, 3(4), 22-27. Retrieved August 12, 2015, from http:// www.ijppsjournal.com/ Vol3Supp14/2411a.pdf

Shriraam, V., Rani, M. A., Sathiyasekaran, B. W. C., \& Mahadevan, S. (2013). Awareness of gestational diabetes mellitus among antenatal women in a primary health center in South India. Indian Journal of Endocrinology and Metabolism, 17(1), 146. Retrieved from http:/ / www.ncbi.nlm.nih.gov/pmc/articles/PMC3659882/

Singh, A., Milton, P. E., Nanaiah, A., Samuel, P., \& Thomas, N. (2012). Awareness and attitude toward diabetes in the rural population of Arunachal Pradesh, Northeast India. Indian journal of Endocrinology and Metabolism, 16(Suppl1), S83. doi: 10.4103/2230-8210.94269

Tabassam, N., Sadaqat, F., Mahmood, K. T., \&Zaka, M., (2010). Prevention and Management of Gestational Diabetes. Journal of Pharmaceutical 
Science and Technology, 2 (12), 404-410. Retrieved from http:/ / www.onlinepharmacytech.info/docs/vol2issue12/JPST10-0212-03.pdf

Ulvi, O. S., Chaudhary, R. Y., Ali, T., Alvi, R. A., Khan, M. F., Khan, M., ... \&Alam, A. Y. (2009). Investigating the awareness level about Diabetes Mellitus and associated factors in Tarlai (Rural Islamabad). J Pak Med Assoc, 59, 798-801. Retrieved from http://jpma.org.pk/full_article_text.php?article_id=1861

Unadike, B. C., \&Chineye, S. (2009). Knowledge, awareness, and impact of diabetes among adolescents in Uyo, Nigeria. African Journal of Diabetes Medicine, 3, 12-14.

Retrieved from http://www.africanjournalofdiabetesmedicine.com

Wee, H. L., Ho, H. K., \& Li, S. C. (2002). Public awareness of diabetes mellitus in Singapore. Singapore Medical Journal, 43(3), 128-134. Retrieved from http://www.singapore-medical.com/ ?gclid = CjwKEAiAhIejBRCKm_fTxIWyyXcSJABXYOXYYFdIuco_swZOIKrAWWRe5xvJxG9kixhh-Lia00X8xoCt6Xw_wcB

Yun, L. S., Hassan, Y., Aziz, N. A., Awaisu, A., \& Ghazali, R. (2007). A comparison of knowledge of diabetes mellitus between patients with diabetes and healthy adults: a survey from north Malaysia. Patient Education and Counseling, 69(1), 47-54. doi: 10.1016/j.pec.2007.06.017 